\title{
EDUCAÇÃO NO/DO CAMPO E AS ORIENTAÇÕES CURRICULARES OFICIAIS NO MUNICÍPIO DE JATAÍ - GO
}

\author{
Education in the country and the official curricular guidelines in Jataí - GO \\ Tatiane Rodrigues de Souza* \\ Evandro César Clemente ** \\ Rosana Alves Ribas Moragas***

\begin{abstract}
* Doutoranda do PPG em Geografia- UFG- Regional Jataí - tati87souza@gmail.com ** Docente do PPG em Geografia da UFG- Regional Jataí - evandroclemente@yahoo.com.br *** Docente do curso de Geografia da UFG- Regional Jataí - rosanarmoragas@yahoo.com.br
\end{abstract}

Recebido em 15/08/2018. Aceito para publicação em 03/09/2018.

Versão online publicada em 20/11/2018 (http://seer.ufrgs.br/paraonde)

\begin{abstract}
Resumo: As discussões no/do campo nos sugerem conhecer que grupos estão envolvidos e que tipo de educação os sujeitos requerem ou qual é o tipo de educação que lhe foram impostas. Para tanto, a pesquisa pretende apresentar uma análise do debate acerca da educação no/do campo e sua inserção em escolas rurais do estado de Goiás, averiguando os direcionamentos contidos nas orientações curriculares oficiais em relação à oferta da educação que ocorre neste espaço. Para a consecução da pesquisa, foi feito levantamentos bibliográficos e trabalho de campo. Por se tratar de uma pesquisa de caráter geográfico, apresentar-se-á exemplos dos eixos temáticos disponíveis nas matrizes curriculares do Ensino de Geografia, exemplos e sugestões e aprofundamentos específicos para alunos que vivem no campo.
\end{abstract}

Palavras-chave: Educação no/do campo; Orientações Curriculares; Educação em Goiás.

\begin{abstract}
The discussions in the country suggest that we know which groups are involved and what kind of education the individuals require or what kind of education they have been given. For this, the research intends to present an analysis of the debate about education in the country and its insertion in rural schools in the state of Goiás, investigating the directions contained in the official curricular guidelines regarding the offer of education that occurs in this space. For the accomplishment of the research, bibliographical surveys and fieldwork were done. Because it is a geographic research, it will present examples of thematic axes available in the Geography Teaching curriculum, examples and suggestions and specific deepening for students living in the country.
\end{abstract}

Key-words: Education in the country; Curricular Guidelines; Education in Goiás.

\section{Introdução}

Dentre os sujeitos residentes no campo brasileiro, podemos destacar: os agricultores familiares ou camponeses, os posseiros, arrendatários, remanescentes de quilombos, ribeirinhos, indígenas e os trabalhadores assalariados ou temporários que, de alguma forma, mesmo residindo muitas vezes nas periferias das cidades, mantêm uma relação com o campo, seja para trabalhar ou como local de moradia no passado.

No caso do município de Jataí, a forte presença da agricultura capitalista provocou transformações significativas em seu espaço agrário, redundando numa intensificação da concentração fundiária, com o predomínio de médias e grandes propriedades rurais, apresentando uma produção bastante expressiva (soja e milho) e de cana de açúcar em grandes propriedades altamente mecanizadas. Este processo provocou significativas mudanças no 
espaço rural e urbano, como a diminuição da população rural, o crescimento urbano e, por conseguinte a redução da produção familiar no campo. Em resultado disso e da falta de valorização da educação pública, as orientações pedagógicas desta educação ofertada no campo se pauta por parâmetros urbanos, sem atentar para as especificidades e necessidades da população ali residente.

Destarte, é necessário repensar e debater as práticas educacionais nas escolas rurais, pensar na valorização dos povos do campo, dos conhecimentos locais, os modos de vida e todos os aspectos socioculturais dos diferentes sujeitos. Realizar as práticas docentes com abordagens que envolvam os alunos com base em sua experiência cotidiana, que conheçam seu espaço, sua realidade e, a partir de então, possam entender e transformar, tornando-se cidadãos participativos, isto é, capazes de se sensibilizarem com o espaço em que vivem.

Objetiva-se neste texto, apresentar uma análise da educação que tem sido ofertada às populações que residem no campo no município de Jataí, que se localiza na Microrregião Geográfica do Sudoeste de Goiás, destacando algumas reflexões da educação no/do campo no estado de Goiás e as orientações curriculares utilizadas pelas Escolas localizadas no campo do município de Jataí GO, ressaltando suas matrizes curriculares. Os procedimentos metodológicos adotados foram o levantamento bibliográfico acerca do tema, análise e consulta em documentos oficiais que orientam o trabalho pedagógico das escolas.

\section{Educação no/do campo no estado de Goiás}

A Educação no Campo é um direito dos indivíduos que vivem nas áreas rurais, é uma educação que deve ser ofertada para assegurar aos alunos o direito à escola. Uma Educação do Campo foi garantida pela lei no 7.352/2010, que instituiu que a escola do campo é localizada em área rural, conforme a Fundação Instituto Brasileiro de Geografia e Estatística - IBGE, ou uma escola que situa nas áreas urbanas é que atenda os povos do campo (BRASIL, 2010).

Isso significa, portanto, que podemos ter uma oferta de Educação do Campo e não necessariamente estar localizado no campo, ou seja, podemos encontrar escolas situadas em áreas urbanas e destinadas a atenderem comunidades residentes no campo.

A Educação do Campo é resultado das lutas das populações que residem neste espaço, junto aos movimentos sociais no campo, que reivindicam o direito de acesso a terra e conseqüentemente seus direitos sociais, entre eles, uma educação voltada para as necessidades e especificidades dos povos do campo.

Para que uma escola seja considerada como "Escola do campo", esta deverá ser pensada a partir das necessidades dos modos de vida dos sujeitos, de maneira a contribuir para o respeito à sua cultura, modo de vida e garantia de melhores condições de existência nos respectivos territórios aos quais eles estiverem inseridos.

Os residentes no campo necessitam de políticas públicas específicas e, portanto, assim como em muitos estados brasileiros, a educação no/do campo no estado de Goiás está inserida em um processo de contradição entre os movimentos sociais e o processo de territorialização do capital, que procura expandir uma educação urbano/capitalista em detrimento do rural.

Para favorecer as práticas capitalistas, as autoridades superiores passaram a ter interesses nas unidades escolares localizadas nas áreas rurais a partir de perspectivas econômicas que viabilizasse o capital. "Essa visão era marcante também no Estado de Goiás, o que pode ser constado em Anais do $8^{\circ}$ Congresso Brasileiro de Educação, realizado em Goiânia, no ano de 1942" (SOUZA, 2012. p.100).

Os programas voltados para agricultura capitalista, sobretudo nas décadas de 1970 e 1980, ampliaram a produção nacional de grãos em Goiás, fator condicionante para a redução dos 
trabalhadores e agricultores familiares, sendo que significativa parcela destes não tiveram muitas opções e foram "obrigados" a desistir de suas terras, dos seus modos de vida e trabalho. Souza (2012, p.101), destaca o fortalecimento do capital, "[...] o agronegócio fortaleceu-se com a criação de várias indústrias e agroindústrias voltadas para ele".

Para a Souza (2012), os pequenos produtores passaram a resistir no campo e a reterritorializar em assentamentos familiares. As resistências desses diferentes sujeitos sociais consolidaram conquistas para o Estado de Goiás. Novas propostas de Educação do campo voltadas para os aspectos culturais vêm sendo debatidas a partir dos movimentos sociais. Atualmente, o Plano Estadual de Educação (PEE), apresenta em um capítulo a importância para uma educação específica para os alunos do campo. Além disso, o estado de Goiás, conta com o Comitê Executivo de Educação do Campo (SOUZA, 2012).

0 debate da Educação no/do Campo no PEE e o Comitê Executivo de Educação do Campo, valoriza a consolidação das escolas no/do campo, que de acordo com o PEE (2015) do Estado de Goiás, o objetivo é manter a modalidade de Educação do Campo, Quilombola e Indígena, escolas que são marcadas pela diversidade das práticas sociais, ressaltando a importância de uma educação para os diferentes sujeitos.

De acordo com Menezes e Silva (2012), o estado de Goiás possuía setenta e uma (71) escolas em áreas rurais. As instituições escolas são administradas pela Secretaria Estadual de Goiás (SEDUC-GO), de acordo com grupos sociais como: Escolas Indígenas que estão em sua maioria localizadas na divisa com estado do Mato Grosso, no município de Aruanã e na divisa entre o estado de Goiás e Tocantins. As escolas camponesas apresentam em maior número seguido pelas escolas de camponeses assentados, enquanto que as Escolas Quilombolas se localizam na mesorregião do Norte Goiano, já ao sul do estado apresenta o menor número de escolas (MENEZES; SILVA, 2012).

Segundo Calaça e Dias (2010), o Sul do estado de Goiás apresenta uma complexa atividade produtiva formada pela produção de grãos e agroindústrias, e ao norte do estado às atividades agrícolas carecem de infraestrutura. Estas considerações pelos autores apresentados esclarece a dispersão e/ou maior concentração das escolas no campo em localidades especificas.

Nas pesquisas realizadas por Menezes e Silva (2012), as autoras não discutem as especificidades de cada escola na modalidade da educação no/do campo, identifica-se que são unidades escolares administradas pela rede estadual, localizadas em áreas de assentamentos ou acampamentos.

Compreende-se que o advento da agricultura capitalista da década de 1990 corroborou para o processo de urbanização, e consequentemente com o fechamento das escolas no campo, ou seja, há o descaso por parte do poder público, que criam estratégias políticas para a redução de recursos para a educação pública no campo.

Entretanto, as populações rurais são resistentes, pois o estado de Goiás possui municípios com unidades escolares localizadas no campo em áreas tradicionais de camponeses. FormosaGO, é um dos municípios que apresenta o maior número de escolas camponesas, cinco das unidades escolares estaduais estão em assentamentos que segundo Souza (2012, p.97), podemos considerar que:

Esse fato é visto como vitória para os camponeses que enfrentaram a luta pela terra, pois é comum os governos estaduais transferirem o alunado para outra escola no campo ou para a cidade, em vez de reconhecerem e institucionalizarem as escolas de acampamentos. Mas constata-se que, nos últimos anos, as escolas nos assentamentos vêm sendo reconhecidas como necessárias ao Estado de Goiás [...]. 
As Escolas Família Agrícola (EFAs) são exemplos de escolas que atuam por uma pedagogia do campo na modalidade da alternância o tempo-escola, tempo comunidade e comunidade-família, uma educação pautada na cultura das famílias, que segundo Nascimento (2003), são escolas que apresenta ações coletivas voltadas para as especificidades dos sujeitos do campo, entre elas temos em Goiás a Escola Família Agrícola de Goiás (EFAGO), a Escola Família Agrícola de Orizona (EFAORI) e a Escola Família Agrícola Uirapuru (EFAU).

Segundo Jesus (2011), os três projetos das EFAs do estado de Goiás, articulam entre suas atividades pedagógica e ensino de apicultura, piscicultura, avicultura, cultivam hortaliças e possuem uma pequena criação de animais, constituindo atividades que visam auxiliar a formação dos alunos numa perspectiva de valorização da vida e do trabalho no campo.

Todavia, as poucas existentes são originárias dos movimentos sociais dos assentados da Reforma Agrária, EFAs que atuam na permanência e por uma educação no contexto dos sujeitos locais, instituições que atuam no envolvimento entre família e comunidade. Embora a EFAs do estado de Goiás sejam uma importante conquista para as população rurais, compreende-se que é preciso que haja políticas educacionais que possam fortalecer a cultura e identidade dos povos do campo e que possa ampliar uma oferta educacional do campo.

\section{Orientações curriculares das escolas no campo}

As escolas localizadas no campo em Jataí GO seguem orientações curriculares reproduzidas fielmente a partir do modelo urbano. Para que haja mudanças no ensino, é necessário a aplicabilidade das Diretrizes Operacionais da Educação Básica do Campo.

As normatizações das escolas localizadas no campo em Jataí-GO são estabelecidas pelos os administradores da Secretaria Estadual de Educação (SEE) e Secretaria Municipal de Educação (SME), os quais mantém suas propostas curriculares voltadas para uma educação urbana. Assim, veremos a seguir os documentos oficiais que direcionam o trabalho nas escolas desde município.

Os Parâmetros Curriculares Nacionais (PCNs) não apresenta nenhuma discussão ou orientação referente a educação do campo. Há apenas descrições pautada na diversidade cultural e da valorização de diferentes grupos sociais, indicando que é preciso "[...] valorizar a pluralidade do patrimônio sociocultural brasileiro, bem como aspectos socioculturais de outros povos e nações, posicionando-se contra qualquer discriminação baseada em diferenças culturais [...]" (BRASIL, PCN,1997, p. 66).

Na reorientação curricular do Estado de Goiás (2009), não há uma discussão específica e delimitada para uma proposta de educação no/do campo, porém, é apresentado em seu texto que as escolas devem realizar suas mudanças e criar propostas por meio do Projeto Político Pedagógico, conforme suas necessidades e particularidades de cada realidade escolar.

De acordo com as matrizes curriculares das escolas pesquisadas, identificou-se que a SEE e a SME utilizam a reorientação curricular do Estado de Goiás (2009) com pequenas adaptações nos conteúdos nas séries iniciais (Ensino Infantil). As demais séries seguem na íntegra os eixos temáticos e as expectativas de aprendizagem. Entretanto, as modificações e adequações poderão ser realizadas para uma proposta de educação no/do campo, de acordo com as Diretrizes Operacionais para as Escolas Campo.

Enquanto que as Diretrizes Operacionais para as Escolas do Campo foram criadas pelas reivindicações dos Movimentos Sociais do Campo, Universidades, Conferência Nacional dos Bispos do Brasil (CNBB), Comissão da Pastoral da Terra (CPT), dentre outros, as populações do campo, a Resolução CNE/ CEB n. 1 de 03 de abril de 2002. Segundo a lei:

A identidade da escola do campo é definida pela sua vinculação às questões inerentes à sua realidade, ancorando-se na temporalidade e saberes próprios dos estudantes, na memória coletiva que sinaliza futuros, na rede de ciência e tecnologia disponível na sociedade e nos movimentos sociais em defesa de projetos que associem as soluções exigidas por essas questões à qualidade social da vida coletiva no país. (BRASIL, 2002, p.1). 
As diretrizes do campo apresentam que os sistemas de ensino devem manter as normatizações que orientam a educação básica no país, desenvolver propostas pedagógicas que valorizem a organização do campo, respeitando as diferenças (BRASIL, 2002).

A criação de uma proposta de educação básica específica para os sujeitos do campo dependerá de política pública educacional visando fortalecer a Educação no/do Campo e a união entre as distintas esferas do poder público na realização desta tarefa.

Podemos afirmar, que é possível adequar os currículos escolares do campo segundo às realidades específicas para os sujeitos do campo, entretanto, as unidades escolares do município não possuem propostas para mudanças curriculares. As instituições de ensino localizadas no campo não apresentaram nenhuma proposta curricular específica e não há adequações de acordo com as populações locais.

Todavia, os educadores podem realizar suas adequações conforme sua formação e disciplina trabalhada. Os professores necessitam de planejamentos específicos para obter resultados para não continuar a reproduzir de forma idêntica à educação urbana. É válido ressaltar que os profissionais da educação não possuem a licenciatura para a educação do campo e nem recebem cursos de capacitação voltado para uma pedagógica específica das populações rurais.

Portanto, por se tratar de uma pesquisa de caráter geográfico, apresentar-se exemplos dos eixos temáticos disponíveis nas matrizes curriculares das escolas de Jataí do Ensino de Geografia, exemplos e sugestões e aprofundamentos específicos para alunos que estudam em escolas localizadas em áreas rurais.

Apresentaremos a verificação dos conteúdos de geografia em uma série de cada nível do Ensino Fundamental II (7ํAno) e Ensino Médio (1ํAno). Serão destacadas apenas três expectativas de cada série a fim de viabilizar as discussões.

No 7음 ano do Ensino Fundamental II apresenta-se no 4을 bimestre do ano letivo, o eixo $A$ industrialização, a urbanização e a modernização no campo, que apresentam as seguintes expectativas de aprendizagem: analisar as consequências socioculturais, políticas, econômicas e ambientais do processo de modernização no campo; caracterizar a estrutura fundiária no Brasil e compreender o processo de concentração de terras no Brasil e suas relações com a expropriação e a exclusão social no campo.

As expectativas do $7^{0}$ ano são todas voltadas para as condições de vida dos sujeitos do campo. Entendemos que os alunos já tenham uma maturidade maior sobre os temas, assim refletir as atuais configurações espaciais das áreas rurais é um bom começo para os alunos compreenderem e valorizarem o rural. Assim, a primeira expectativa é ampla, o professor poderá trabalhar textos sobre os distintos grupos sociais e culturais do campo (indígenas, caboclos, agricultores familiares, pescadores, assentados acampados), enfatizar como esses povos foram sendo expropriados de suas terras, resultados da "modernização".

Ao consideramos a estrutura fundiária, é possível compreender o processo de concentração de terras no Brasil, conforme a terceira expectativa. É relevante destacar a exclusão dos sujeitos do campo e levar aos alunos a refletirem que o nosso país apresenta grandes extensões de terras, as quais estão nas mãos de poucos trabalhadores, isto é, a terra passou a ser espaço de luta "[...] dos desapropriados nas grandes obras do Estado, dos "brasiguaios", dos sem-terra, dos seringueiros, dos bóias-frias e da presença do "trabalho escravo" particularmente nas carvoarias (OLIVEIRA, 1996, p.54).

No $1^{\circ}$ Ano do Ensino Médio é destacado no 3 o Bimestre o eixo Social Cartográfico Físico territorial, apresentando as seguintes expectativas de aprendizagem: conhecer, conceituar as categorias de análise da Geografia e estabelecer correlações para compreender o funcionamento do Espaço Geográfico; entender que a paisagem é o ponto de partida para o estudo do espaço geográfico; compreender o espaço geográfico como o conjunto indissociável de sistemas de objetos (redes técnicas, prédios, ruas) e de sistemas de ações (organização do trabalho, produção, circulação, consumo de mercadorias, relações familiares e cotidianas), que revelam as práticas dos diferentes grupos humanos que nele produzem, lutam, sonham, e fazem a vida caminhar.

Nos conteúdos iniciais do 1ํㅗㄹie do Ensino Médio, as discussões teóricas iniciam-se a partir dos principais conceitos/categorias a Geografia e do seu ensino: Lugar, espaço, território, paisagem e região. Após conceituar os conceitos/categorias de análises da Geografia, é relevante que o professor faça uma explanação sobre todos eles, porém, buscando direcioná-las para o espaço de vivência dos alunos, fazendo com que os estudantes compreendam melhor o lugar das suas vidas, território de luta, paisagem 
que muda e se transforma, regiões que estão conectadas exercendo influências e espaço que determinam diferentes formas de apropriação.

Ao estabelecer a segunda expectativa, abordar que a paisagem contempla todas as transformações na sociedade, é tudo que possa ser visto, seja uma paisagem natural ou construída. Propõe-se realizar questionamentos sobre como eram as paisagens nas áreas rurais e como atualmente são caracterizadas, destacando as principais mudanças que ocorreram ao longo das últimas décadas.

A terceira expectativa é ampla, sendo possível ampliar a abordagem, há a sugestão para trabalhar as relações de trabalho, tanto do campo como na cidade, pautadas e discutidas separadamente. Em seguida, realizar debates que campo e cidade são espaços que se complementam e são interdependentes. Correlacionar os preços dos alimentos na cidade com a produção do campo, que a cidade depende do campo para ter acesso a recursos primários e o campo depende da cidade na disponibilização de produtos tecnológicos, ou seja, apresentam uma dependência mútua.

Apesar dos desafios para se construir e consolidar um currículo específico do campo as escolas e as autoridades competentes podem elaborar currículos para os alunos que vivem no campo de acordo com, a vida social destes, tempo, cultura e identidades, a partir dos saberes e fazeres, articular os currículos para sujeitos do ensino infantil e de jovens e adultos. Ademais, é necessário que haja educadores formados e capacitados para atuarem com as especificidades dos povos do campo (ARROYO, 2012).

Entendemos que a educação do campo é uma estratégia social capaz de fortalecer o trabalho e os saberes destes sujeitos, uma escola que visa os direitos, a política e os aspectos socioculturais desta população. Segundo Arroyo (2009, p.7), é preciso educar o trabalhador do campo, “[...] porque são sujeitos de direitos. Os direitos que estão aqui destacados nas paredes, destacados nas músicas, nas bandeiras, na mística: terra, justiça, igualdade, liberdade, trabalho e dignidade, saúde, educação..."

\section{Considerações Finais}

No estado de Goiás, assim como em todo o território brasileiro há um campo diversos e cheio de riquezas culturais, por essa razão, as políticas educacionais precisam contribuir para uma educação de qualidade e preparar o indivíduo do campo para a vida e o trabalho. Para tanto, é necessário entender as diferenças entre as classes sociais, visando fazer frente às necessidades de todos os sujeitos do campo.

É possível afirmar que no município de Jataí-GO as escolas são rurais, apresentando um currículo urbanocêntrico, ou seja, o debate por uma educação no/do campo não é de conhecimento prático para as autoridades ali existentes e para os educadores destas unidades escolares. Deste modo, é preciso que haja formação e conhecimento teórico da pedagogia do campo, para que os professores e gestores possam aturarem de acordo com as especifidades dos sujeitos que vivem em áreas rurais, além disso, é preciso que as populações do campo entre em movimento para a consolidação de políticas públicas por uma educação de direitos.

O grande desafio para a consolidação da Educação do campo em Jataí é que as classes dominantes viabilizaram novas funções econômicas neste município, que por sua vez, passaram a transformar este espaço por um território do capital, de pouca gente expropriando inúmeros sujeitos do campo, que não prioriza uma educação emancipatória e específica dos sujeitos do campo, reproduzindo nas escolas uma pedagogia urbana, a qual não valoriza os interesses e as necessidades das população do campo, uma educação amparada pelo Estado com políticas educacionais voltadas para o interesse das classes superiores.

\section{Referências}

CALDART, R. S; MOLINA, M. C (orgs). Por uma Educação do Campo. 4. ed. Petrópolis, RJ: Vozes, 2009.

ARROYO, M. G. Tempos humanos de formação. In.: CALDART, R. S, et al. (orgs.). Dicionário da Educação do Campo. Rio de Janeiro, São Paulo: Expressão Popular, 2012.

BRASIL. Diretrizes Curriculares Nacionais Gerais para a Educação Básica: diversidade e inclusão. Brasília: 
MEC, 2013.

Diretrizes Operacionais Para a Educação Básica nas Escolas do Campo. Brasília: MEC, 2002.

- Ministério da Educação e do Desporto. Secretaria de Educação Fundamental. Parâmetros Curriculares Nacionais: Geografia. Brasília: MEC / SEF, 1997.

CALAÇA. M; DIAS. WAGNER.A. modernização do campo no cerrado e as transformações socioespaciais em Goiás. Revista de geografia agrária, v.5, n.10, ago. 2010.

JESUS, J. N. de. A pedagogia da alternância e o debate da educação no/do campo no estado de Goiás. Revista NERA (UNESP), v. 18, p. 07-20, 2011.

MENEZES, P.K. ; SILVA, R. L. B. R.da. Escolas do campo de Goiás. In: XXI Encontro Nacional de Geografia Agrária, 2012, Uberlândia. XXI ENGA - Territórios em Disputa: Os desafios da Geografia Agrária nas contradições do desenvolvimento brasileiro. Uberlândia: UFU, 2012.

NASCIMENTO, C.G.Educação do Campo e Escola Família Agrícola de Goiás: o caminhar da teimosia de um movimento social educativo. Curitiba: Revista Diálogo Educacional, volume 4, no 08 (jan/abr.), PUC-PR, 2003.

OLIVEIRA, A. U. de. A agricultura camponesa no Brasil. São Paulo: Contexto, 1996.

PEE. Plano Estadual de Educação de Goiás, 2015. Lei № 18.969, de 22 de julho de 2015.

SOUZA, F. E. As "Geografias" das escolas no campo do município de Goiás/GO: Instrumento para valorização do território do camponês. 2012. 380 f. Tese (doutorado em Geografia). Programa de pós graduação em Geografia. Universidade Unespe - Presidente Prudente - São Paulo, 2012. 